\title{
The Study of English and Chinese Numerical Idioms and Their Translation*
}

\author{
Yuan Kong \\ Department of Foreign Languages, Jining Medical University, Jining, China
}

\begin{abstract}
Numerical idioms have rich cultural connotations and are closely connected with culture. Along with the development of China's reform and opening up policy, intercultural communication tends to be wider. Contrastive studies of language-culture have become increasingly important. This article is mainly a probe into the English and Chinese numerical idioms from the perspectives of definition and cultural characteristics of English and Chinese idioms and meanwhile makes a detailed analysis of the translation of numerical idioms of both English and Chinese languages with practical and theoretical effect. It will help us with language teaching and learning, translation and intercultural communication if we have a proper understanding of the differences between both English and Chinese numerical idioms. Only by mastering the deep cultural meaning of numerical idioms can we make the translation more vivid and expressive, thus effectively improving the ability of intercultural communication.
\end{abstract}

Index Terms - numerical idioms, definition, cultural characteristics, translation

\section{INTRODUCTION}

An idiom is a set phrase or short sentence abstracted from people's long-term use. It is the crystallization of human wisdom. In terms of its general meaning, it includes allegorical phrases, colloquialisms, slang expressions, proverbs and so on. English and Chinese have a large number of numerical idioms that vividly throw great light on the different cultural characteristics between the two nations. Different notions of human thoughts have a decisive effect on perception and orientation of the different numbers. Numerical idioms have the profound national cultural deposits and special cultural sources, whereas religious convictions, history, cultural tradition and customs all together influence the cultural meanings of the English and Chinese numerical idioms.

\section{DEFINITION OF ENGLISH AND CHINESE IDIOMS}

Any language has its own long-term accumulated and stereotyped phrases or short sentences that are used to describe popularly and vividly the world. They are called "idioms" in English and "shu2 yu3"in Chinese. To make an accurate definition of numerical idioms, we must understand the concept of English and Chinese idioms first.

The term "Xi1" Yu3" is a Chinese counterpart of "idiom" in English. In the Chinese-English bilingual Modern Chinese Dictionary (2002), English “idiom" is semantically equivalent to Chinese "shu2 yu3". English word "idiom" in English dictionaries is defined as follows:

Oxford Advanced Learner's English-Chinese Dictionary (1997): a phrase or a sentence whose meaning is not clear from the meaning of its individual words and which must be learnt as a whole unit.

Cambridge International Dictionary of English with Chinese Translations (2001): a group of words in a fixed order having a particular meaning, different from the meaning of each word understood on its own.

Longman Dictionary of Contemporary English (English-Chinese) (2009):a group of words with the meaning of its own that is different from the meanings of each separate word put together.

The Chinese word "shu2 yu3" (idiom) in Chinese dictionaries is defined as follows:

Ci Hai (1999): fixed phrases or sentences (including idioms, proverbs, sayings, aphorisms, locutions, two-part allegorical sayings and the like), whose organization can not be changed arbitrarily, should be understood as a whole.

The Contemporary Chinese Dictionary (Chinese-English) (2002): fixed phrases with unchangeable ingredients and unique structure, which should be applied as a whole but could not be analyzed by usual word formation. For example: "ban4 jin1 ba1 liang3" (six of one and half a dozen of the other); "ba1 jiu3 bu4 li2 shi2" (pretty close).

It can be seen from the definitions above that two characteristics of both English and Chinese idioms are the unity of meaning and the fixity of grammatical structure. The former means that their meaning is semantically indivisible, not a simple sum of the meaning of each word, namely, literal meanings. Therefore, idioms must be understood as a whole. The latter means that each part of the idioms is fixed and irreplaceable. We have to point out: Broadly, "idiom" includes set phrases, colloquialisms, proverbs, slang expressions and others. (Note: the generalized "idiom", often interpreted

\footnotetext{
${ }^{*}$ Funding Source: JMC Scientific Research Project (JY2013RW032)

${ }^{1}$ In this article, for the purpose of an easier and labor-saving intercultural communication, all the Chinese characters are represented by their pronunciations, that is, Chinese "pinyin". The numbers from 1 to 4 stand for the four kinds of Chinese tones.
} 
into Chinese "xi2 yu2", is generally equivalent to "shu2 yu3" in Chinese in concept. However, "shu2 yu3" in Chinese has a rather broad concept which refers to set phrases or sentences. Its organization can not be changed in a general way and must be understood as a whole. The Chinese "shu2 yu3" is classified by domestic scholar Wang (1997) into idioms, proverbs, aphorisms, locutions, two-part allegorical sayings and colloquialisms according to the nature, among which proverb is regarded as the principal part. Two-part allegorical saying is a kind of special form in Chinese, which is made up of approximate riddle and mystery including metaphoric meaning and homophonic pun. There is no such a form in English idioms); Narrowly, "idiom" refers to "cheng2 yu3" in Chinese. Although this kind of English idiom is symmetrical in structure and coordinate in rhythm, it doesn't contain the form of "four words case" that is a significant difference from Chinese "cheng2 yu3", which takes "four words case" as its basic form with harmonious syllables and level and oblique tones.

From the above definitions, English word "idiom" is in line with Chinese word "shu2 yu3" mostly. The common feature of both English and Chinese idioms is that: they are long-term accumulated, fixed phrases or short sentences with specific meaning which could not be deduced from the meanings of their components. This is the result of convention. In order to study idioms easier, here, "idiom" refers to English "idiom" and Chinese "shu2 yu3", including phrases, proverbs, colloquialisms, maxims, locutions and so forth.

The current definitions of numerical idioms are as follows:

Zhang (1999): set phrases composed of numbers together with other words. This is a common means of expression shared by both English and Chinese.

Chen (1999): phrases composed of cardinal numbers, ordinal numbers and other words.

Yin \& Han (2004): idioms containing numbers.

From the above, as an important part of idioms, numerical idioms are composed of cardinal numbers, ordinal numbers and other words with numerical meanings such as Chinese words "shuang1" (double or pair) and "ban4" (half), English words "double", "every" and "a". (Note: "a" and "one" are cognates expressing the same meaning). In this thesis, numerical idioms have two types: sentences and phrases with the exception of two-part allegorical sayings (unique to Chinese). English numerical idioms include set phrases, colloquialisms, proverbs, slang expressions and so on, while Chinese numerical idioms include phrases, proverbs, maxims and aphorisms, sayings and others.

\section{Cultural CharaCTERISTICS OF ENGLiSh AND CHINESE IDIOMS}

Culture generally refers to the totality of the material possessions and spiritual wealth created by human beings in the course of social development. "Culture", in terms of cultural linguistics, connotes cultures in spiritual and institutional forms (Dai, 1996). Spiritual culture is formed on the basis of material culture, mainly including the perceptions, modes of thinking, national personalities, national psychology, values, religious beliefs, literature and arts, aesthetic standards, customs and folkways, etc. accumulated in the long-term development of culture and history. While "the essence of spiritual culture involves the ideologies and concepts best expressed in philosophical thoughts" (Gu \& Lu, 2002, p.73). Institutional culture includes institutions of life, society, family, etc.

Different people have established their specific cultural systems in their living circumstances. Meanwhile, they are also shaped by their cultures. Language is a special form of culture, bearing strong cultural attributes, cultural values and cultural functions. The cultural attributes of language are reflected in the fact that language is a cultural product with its formation and development inseparable from the culture (Deng \& Liu, 1989).

The cultural values are mainly shown in the forms of reflection, transmission and supervision of cultures. In terms of reflection of culture, such aspects as the differences of English and Chinese languages in structure and connotation are exemplifications; in terms of transmission of culture, they are mainly embodied in the fact that language is a vector of national cultures on one hand-for example, we can find the distinctive cultural origins and values of the two peoples from the numerous English and Chinese idioms - and the use of a language takes national culture as the background on the other hand. This cultural background shown in language communications is a prerequisite for effective communications. Language is the mode of national culture and the symbol system that forms the national culture. A people's language manifests a people's culture, and the linguistic differences reflect the cultural differences. In order to have a thorough understanding of the cultural functions of a language and the influence of culture on language, we must make a profound disclose of the relationship between language and culture. A linguistic communication is also a cultural communication. The intercultural communication means decoding in another culture the information coded in one culture as there are always some underlying additional meanings restricted by the national culture, which is paralinguistic information behind any language (Guan, 2002). Language is the vector and container of culture. To put it briefly, language can be used to describe every aspect of culture. As the vector and chief expression of culture, language is restricted by culture. Language develops with the development of a nation, and is a constituent of social and national culture. Different nations live in different ecological, material, social and religious circumstances, and different linguistic circumstances produce a number of different contextual elements such as social culture, conventions and folkways, and customs and practices. Different cultural backgrounds determine the differences in people's communicative ways and habits. Language is deeply rooted in a nation's organism, and takes an active part in all of the nation's spiritual activities as an important factor that forms the common psychological makings of the nation. The characteristics of a nation's social culture, historical traditions, living style, living circumstances and religious beliefs as 
well as its taste, interest, temperament, personality, sentiment and ability can all be reflected in the language. Language is a window for the perception of human psyche, through which a nation's psychological state, cognitive style and thinking trajectory could be perceived.

As an important component of a language's vocabulary, almost every idiom suggests a story and cultural background. Therefore, the understanding of the cultural connotation of idioms directly influences and restricts our grasp and use of idioms. It is especially of great realistic significance in intercultural communication. What is cultural connotation? We must, therefore, first make clear of what is connotation. According to the explanations of A Dictionary of Linguistics and Phonetics compiled by David (2001), and An English-Chinese Dictionary of Linguistics compiled by Lao (2004) and some other experts, connotation is originally a philosophical and logic term referring to the total content a conception can cover, that is the totality of the essential attributes that a conception reflects, as opposite to denotation. Nowadays it is usually used to construct the theoretical framework of linguistics and semantics and refer to a group of defined features that can decide a word's adaptability. Cultural connotation means considering the essential attributes reflected by a conception as a whole from the perspective of culture. Idioms have distinctive semantic and pragmatic characteristics as well as many functions, whereas the study of connotation involves a number of subjects such as lexicology, semantics, pragmatics, etymology, social linguistics, historical linguistics, cognitive linguistics, cultural linguistics and so on. Therefore a study of the cultural connotation of English and Chinese idioms must be started from multiple subjects, multiple perspectives and multiple levels so that substantial results can be achieved. Besides, except for its purely rational substance, a word also bears some kind of communicative value by virtue of its denotation. That is, when people use or hear a word, the word can suggest experiences in "the real world". So understanding of connotation varies with different people, different ages, as well as different societies, countries and times. Different cultural groups (societies and countries) show distinct psychological characteristics of personal and national preference and abhorrence in the face of the same object or conception due to their different natural ecological circumstances, economic development levels, political constitutions and ideologies. We define this kind of connotation originating from cultural backgrounds as cultural connotation of idioms (Zhang, 2007).

Both English and Chinese languages with long histories contain abundant idioms which not only carry explicit folk cultural information but also suggest profound national cultural implications. To disclose the connotations of English and Chinese idioms is like opening a portrait of the national history and culture, revealing the ethnic customs of the speakers of the two languages as well as the profound impacts history and culture have exercised on the languages. English and Chinese idioms, as a processed and refined language form, are the essence of languages. Idioms are usually brief and accurate, beautiful and vivid, profound in meaning and rich in humor, whereas the subtle use of metaphors is one of the major contributors to these characteristics. Idioms have rich connotations, either explicit or implicit. Idioms are closely related to a nation's culture. The metaphors involved are especially richer in strong colors of national cultures. "Considered from the perspective of social culture, language is the code for culture, whereas idioms are the most economical and effective ones among the linguistic codes since the cultural contents harbored in idioms are historically profound and realistically broad" (Cui, 1997, p.18). As the core and essence of language, idioms are the crystallization of a culture. It is safe to say idioms are more typical and representative in reflecting cultural differences than any other linguistic element. Any language in the world contains great numbers of idioms which not only share some similarities but also show inevitable differences resulted from the differences in their cultural backgrounds. The great differences between Chinese and Western national cultural traditions determine the sharp contrasts in the characteristics of their idiom cultures. Only after making clear the cultural differences and similarities between English and Chinese idioms can we better grasp and use them.

\section{The Translation of English and Chinese Numerical IDiOMS}

Language is not only the carrier of culture, but also resides in culture. The culture is spread widely by means of language. Most numbers in English and Chinese numerical idioms are carrying certain cultural elements, which is what we often call cultural load words. Therefore, in the translation of numerical idioms, our first task is to strive to explore their cultural roots and make correct comprehensive interpretation of their cultural information. Then, we could locate the cultural load words corresponding to the numbers rather than to the representation. Meanwhile, we should take various effective strategies of translation according to the following principle: domestication is primary, foreignization is auxiliary. If we find an English numerical idiom corresponding to a Chinese numerical idiom occasionally, literal translation could be applied. Some examples are as follows:

A cat has nine lives: mao1 you3 jiu3 ming4

be in twos and threes: san3 san3 liang2 liang2

A stitch in time saves nine: yi1 zhen 1 ji2 shi2 sheng4 jiu3 zhen 1

A drop in the ocean: cang1 hai3 yi1 li4

Two heads are better than one: yi 1 ren 2 bu4 ji 2 er 4 zhi 4

One bird in hand is better than two in forest: yi1 niao3 zai4 shou3 sheng4 guo4 shuang1 niao3 zai4 lin2

Kill two birds with one stone: yi1 shi2 er4 niao3/ yi1 jian4 shuang1 diao1

Language is a reflection of the objective world and a kind of social and cultural phenomenon. The linguistic and cultural factors of Chinese and English together dominate the whole process of translation between them and also 
determine semantic orientation. Actually, cultural factor plays a more important role than linguistic factor does. Mr. Wang Zuoliang said, it is better to study a language through the study of its culture. What a translator meets in the process of translation are not simple words but two cultures. There exist a huge number of numerical idioms with seemingly similar meanings but actually with different social and cultural connotations in English and Chinese, so we have to try to find ways to fill the cultural loss of connotative meanings in our translation. For example, there are many numerical idioms containing "five" in Chinese. "Five" has its original numerical meaning, but it evolves into a figurative meaning. The cultural source of the word "five" is closely associated with the number "five". For instance, in the Chinese idiom "wu3 guan1 duan1 zheng4", "wu3 guan1" refers to "mouth, nose, eyes, ears and body" originally. But now it only refers to four facial organs. With the development of culture, some Chinese idioms with number "five" have merely the figurative meaning expressing the meaning of "complete, various, all and so on". Therefore, they can not be translated into English by using the English word "five" directly. Otherwise, it will deviate from the implied meaning in Chinese and even cause misunderstandings. Some examples are as follows:

wu3 da4 san 1 cu1: tall and sturdy

wu3 zang4 liu4 fu3: the vital organs of the human body

wu3 guan1 duan1 zheng4: have regular figure

wu3 guang1 shi2 se4: multi-colored; all sorts and kinds; of all colors; of great variety.

wu3 ti3 tou2 di4: admire sb. from the bottom of one's heart; worship sb.

wu3 hu2 si4 hai3: a11 corners of the land; all over the country/world

wu3 gu3 feng1 deng1: have an abundant harvest of a1I

wu3 hua1 ba1 men2: of a wide/rich variety; varied and well assorted

Similarly, the Chinese character "shi2" (ten) has no relation to the English word "ten" in culture. The Chinese character "shi2" (ten) means "all of, enough, greatest", while the English word "ten" has no such meaning. Therefore, proper English words should be chosen to express the meaning of "all of, enough, greatest". Some examples are as follows:

shi2 quan2 shi2 mei3 (signifying perfect): leave noting to be desired/ satisfactory in everyway

shi2 na2 jiu3 wen3 (do sth. with accuracy and assurance): beyond a shadow of doubt, almost certain

shi2 yang2 jiu3 mu4 (less people more officials): more officials than people under certain

shi2 nian2 han2 chuang1 (painstaking and long-term study): study hard and long

Through the study on the translation of numerical idioms, it can be found: most Chinese numerical idioms have no corresponding English ones except for a few. And in many cases, these English expressions translated from Chinese numerical idioms are just simple combination of common words because the cultural loss of target language will inevitably cause the lack of format and meaning. Of course, only if we adopt free translation on the basis of understanding the specific meaning and cultural background and the cultural roots of numbers through careful analysis and in-depth research, then determine the appropriate forms of expressions to complement the cultural loss of numbers in translation, can we avoid failures in intercultural communication to the uttermost. For instance, in Chinese, the numerical idioms with "seven" and "eight" have no corresponding ones in English. They ought to be translated in terms of their implied meanings. Some examples are as follows:

qi1 shou3 ba1 jiao3: in a flurry; all get busy

qi1 shang4 ba1 xia4: undecided; restless; be agitated

luan4 qi1 ba1 zao1: in a mess; disorder

qi1 zui3 ba1 she2: all talking in conclusion; all talking at once

qi1 niu3 ba1 wail: crooked; uneven; disorderly; irregular

qi1 pin 1 ba1 cou4: scrape together; piece together; rig up

qi1 ling2 ba1 luo4: throw into disorder

qi1 zhe 2 ba1 kou4: various deductions

The same case can also be found in translation of some Chinese numerical idioms with "nine". For example:

jiu3 quan2 zhi1 xia4: after death

shi2 na2 jiu3 wen3: almost certain; practically certain; unquestionable

jiu3 si3 yi1 sheng1: a narrow escape from death

shu3 jiu3 han2 tian 1: cold as hell; the coldest days in winter

jiu3 xiao1 yun2 wai4: beyond the highest heavens

jiu3 zhou1 fang1 yuan2: all over China

jiu3 niu2 yi1 mao2: a drop in the ocean

shi2 zhi1 ba1 jiu3: most likely

jiu3 jiu3 gui1 yi1: after all; when all is said or done

jiu3 niu2 er4 hu3 zhi1 li4: tremendous effort

The numbers of English idioms often have specific meaning, while that of Chinese idioms often have metaphorical meaning. In many cases, their figurative meanings are seemingly in harmony but actually at variance or even different. We can not take the idioms too literally. Some examples are as follows:

one-night stand: xun2 hui2 yan 3 chu 1 (making a performance tour) 
dressed up to the nines: chuan 1 zhuo2 jiang3 jiu1 (be dressed well)

on all fours think twice: zai4 san 1 kao3 lv4 (turn over)

two-time: yi1 ye4 feng1 liu2 (a night of romance)

in one or two words: san 1 yan2 liang3 yu3 (in a few words)

at the eleventh hour: zui4 hou 4 shi2 ke4 (at the last moment)

in two minds: san 1 xin 1 er4 yi4 (half-hearted)

the seventh day: an1 xi1 ri4 (Sabbath day)

New brooms sweep clean: xin1 guan1 shang4 ren4 san1 ba3 huo3 (A new official applies strict measures.)

A man may lose more in an hour than he can get in seven: de2 lai2 jian1 nan 2 shi1 zhi1 yi4 (hard gain easy lost)

be two/ ten a penny: fei 1 chang 2 pian2 yi4/ yi1 wen2 bu4 zhi2 (very cheap)

Two can play the game: yil ge4 ba1 zhang3 pai1 bu4 xiang3----gu1 zhang3 nan2 ming2 (a two-part allegorical saying)

nine to five: zhao1 jiu3 wan3 wu3 (normal working hours in an office)

One boy is a boy, two boys half a boy and three one: yilge4 he 2 shang 4 tiao1 shui3 chi1, liang 2 ge 4 he 2 shang 4 tai2 shui3 chi1, san 1 ge4 he2 shang4 mei2 shui3 chi1 (a fable)

One hand washes another: you3 lai2 you3 wang3, hu4 xiang1 bang1 mang2 (help mutually)

Keep a thing seven years and you'll find a use for it: dong1 xi1 bao3 cun2 shi2 jian 1 chang2, zhong1 yu2 pai4 shang4 hao3 yong4 chang3 (keep things for a long time and finally come in handy)

In Theories and Techniques in Translation Professor Fan (1985) points out, in general, phrases or sentences of two languages are hardly equivalent; quite a few of them are correspondent; most of them are neither equivalent nor correspondent. Translation means not only the transformation from one kind of words to another, but also involves the history and culture, religion, customs, social background as well as value hidden in the source language. This especially applies to translation of numerical idioms with national colors and local characteristics. Through the exploration of the cultural roots and interpretation and contrast of the cultural information of English and Chinese numerical idioms, it can be clearly found: numbers in both English and Chinese idioms have obvious national and cultural imprint. Different customs, religions, cultural traditions will affect the cultural figurative meaning of numerical idioms. To interpret the cultural differences between Chinese and English numerical idioms correctly is of great importance to the study of foreign languages, the mutual translation between English and Chinese, foreign language teaching and research, intercultural communication, etc. A deep understanding of cultural connotations of numerical idioms helps to make translation more vivid and more expressive, and thus promoting the intercultural communication effectively.

\section{REFERENCES}

[1] Adam, M. (1972). Idiom structure in English. The Hague: Mouton.

[2] An, M. H. (2008). A Comparison of English and Chinese Numerical Idioms. Jilin: Yanbian University Press.

[3] Andre, S. (1990). Idiomatic blocking and the elsewhere principle. Hillsdale, NJ: Lawrence Erlbaum Associates.

[4] Andre, S. (1995). The syntactic behavior of idioms. Hillsdale, NJ: Lawrence Erlbaum Associates.

[5] Bates, D. G. \& F. Plog. (eds.) (1990). Cultural anthropology (3rd ed.). New York: McGraw-Hill.

[6] Biguenet, J. \& R. Schulte. (1989). The craft of translation. Chicago: The University of Chicago Press.

[7] Bloomfield, L. (1985). Language: an introduction to the study of speech. Beijing: The Commercial Press.

[8] Brower, R. (1966). Open translation. New York: Oxford University Press.

[9] Chomsky, A. N. (1979). Syntactic structures. Beijing: China Social Sciences Press.

[10] Christiane, F. (1993). The determiner in English idioms. Hillsdale, NJ: Lawrence Erlbaum Associates.

[11] Chomsky, A. N. (1986). Aspects of the theory of syntax. Beijing: China Social Sciences Press.

[12] Collins, V. H. (1957). A book of English idioms. London: Longman.

[13] Cuddon, J. A. (ed.) (1998). A dictionary of literary terms and literary theory. Oxford: Blackwell Publishers Ltd..

[14] Dan, S. \& W. Deidre. (2001). Relevance: communication and cognition. Beijing: Foreign Language Teaching and Research Press.

[15] Eberhard, W. (1990). The dictionary of symbols in China's culture. Wuhan: Hubei Lexicographical Press.

[16] Edwin, D. \& W. E. Williams. (2002). Seeking the nature of idiom. USA: Oxford University Press.

[17] Edwin, W. (1987). On the definition of word. Cambridge, Mass.: MIT Press.

[18] Elser, A. (1992). The human venture (2nd ed.). Englewood Cliffs, NJ: Prentice-Hall.

[19] Fernando, C. (1996). Idioms and idiomaticity. Oxford: Oxford University Press.

[20] Fisher, M. P. \& R. Luyster. (1991). Living religions. Englewood Cliffs, NJ: Prentice-Ha11.

[21] Frank, N. M. (1991). World philosophy: essay-reviews of 225 major works. Beijing: China Radio \& Television Publishing House.

[22] Frank, V. G. (1995). In idioms: structural and psychological perspectives. Hillsdale, New Jersey: Lawrence Erlbaum Associates.

[23] Garald, G., Klein, E., G. Pullum \& I. Sag. (1985). Generalized phrase structure grammar. Cambridge, Mass.: Harvard University Press.

[24] George, L. \& M. Johnson. (1980). Metaphors we live by. Chicago: Chicago University Press.

[25] Halliday, M. A. K. \& R. Hasan. (1985). Language, context, and text. Aspects of language university in a social-semantic perspective. Geelong: Deakin Press.

[26] Hatin, B. \& I. Mason. (1991). Discourse and translaton. London: Longman.

[27] Heacock, P. (2003). Cambridge dictionary of American idioms (Dictionary). London: Cambridge University Press. 
[28] Hockett, C. F. (1986/1987). A course in modern linguistics. Beijing: Beijing University Press.

[29] James, D. F. (2004). High-field neuroanatomy. USA: Lippincott Williams \& Wilkins.

[30] Kovecses, Z. (1986). Metaphors of anger, pride, and lobe: a lexical approach to the structure of concepts. Amsterdam: John Benjamins Pub. Co.

[31] Laurie, B. (1986). English word-formation. London: Cambridge University Press.

[32] Liu, B. S. (ed.) (1981). A short history of English literature. Shanghai: Shanghai Foreign Language Education Press.

Yuan Kong received her M.A. degree in linguistics. She is currently a lecturer at the Department of Foreign Languages, Jining Medical University, Jingning, China. She teaches various subjects including: English intensive reading, English extensive reading, listening, nursing reading and so on. Her research interests mainly include English language teaching, applied linguistics, cross-cultural communication, etc. 